Article

\title{
Effect of Crumb Rubber, Epolene (EE-2), and Date Palm Ash as Modifiers on the Performance of Binders and Mixtures: A Sustainable Approach
}

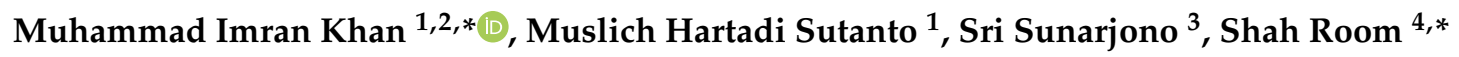 \\ and Nur Izzi Md Yusoff ${ }^{5}$ \\ 1 Department of Civil \& Environmental Engineering, Universiti Teknologi PETRONAS, \\ Seri Iskandar 32610, Malaysia; muslich.sutanto@utp.edu.my \\ 2 Department of Civil \& Environmental Engineering, College of Engineering, King Faisal University, \\ Al-Ahsa 31982, Saudi Arabia \\ 3 Faculty of Engineering, Universitas Muhammadiyah Surakarta, Jawa Tengah 57162, Indonesia; \\ Sri.Sunarjono@ums.ac.id \\ 4 Department of Civil Engineering Technology, University of Technology, Nowshera 24100, Pakistan \\ 5 Department of Civil \& Structural Engineering, The National University of Malaysia, \\ Selangor 43600, Malaysia; izzi@ukm.edu.my \\ * Correspondence: Muhammad_17007177@utp.edu.my (M.I.K.); shahroom@uotnowshera.edu.pk (S.R.)
}

Received: 10 October 2019; Accepted: 6 November 2019; Published: 18 November 2019

\begin{abstract}
The only type of conventional bitumen (PG 64-10) available in the Kingdom of Saudi Arabia (KSA) does not meet the temperature requirements of most of the kingdom's regions. Hence, the binder needs to be modified to improve the performance of flexible pavements at high temperature and heavy traffic loading. In order to meet the requirements of the Superpave Performance Grade (PG), crumb rubber (CR), epolene (EE-2), and date palm ash (DPA) were used as asphalt additives in different percentages $(4 \%, 8 \%, 12 \%$, and $16 \%$ by weight of bitumen). Viscosity and rheological tests as well as stability and indirect tensile tests were performed on binders and asphalt mixtures. The binders modified with CR, EE-2, and DPA showed improved rheological and performance properties as compared to conventional binder. Similarly, the PG of conventional asphalt was upgraded with the addition of different percentages of the modifiers. Furthermore, this study also aimed to help the environment by minimizing and recycling wastes in road construction processes to achieve sustainability.
\end{abstract}

Keywords: crumb rubber; date palm ash; epolene; Marshal quotient; bitumen rheology; modified bitumen

\section{Introduction}

Waste production is increasing significantly in the Kingdom of Saudi Arabia (KSA) due to the increasing population and rapid urbanization. Currently, recycling waste processes are very limited, resulting in all of it being disposed of in landfills, automatically affecting human health and the living environment. A simple solution and the most practical way of recycling is to utilize it in the construction of flexible pavements. In the KSA, flexible pavements show distress during the initial period of service due to the heavy vehicular loading and severely high temperature in the summer. The reason behind the utilization of conventional PG 64-10 bitumen (which does not satisfy the performance requirements at high temperature in most of the Kingdom's regions) is because the required high-performance grade (PG) in most of the Kingdom is PG 70 and above [1]. Utilizing conventional bitumen without 
modification would lead flexible pavements to suffer from distress in terms of rutting, fatigue cracks as well as other failures before reaching the end of its design life.

Various additives/modifiers have been used to improve the performance of the conventional bitumen under different loading and temperature conditions such as polyethylene (e.g., LDPE and $\mathrm{HDPE})$, crumb rubber (CR), styrene-ethylene/butylene-styrene (SEBS), polypropylene (PP), and ethylene-vinyl acetate (EVA). All of these polymers/modifiers contribute to the improvement of bitumen properties, yet there are some disadvantages which restrain future advancements in polymer-modified bitumen due to the fact of its high cost, ageing, and storage problems [2-4]. The performance of an asphalt mixture modified with high-density polyethylene showed a significant improvement against rutting as indicated by the high value of stability and Marshall quotient $[4,5]$. Similarly, an LDPE-modified asphalt can also enhance the fracture toughness, indirect tensile, and compressive strength of asphalt mixes [6]. A study revealed that bitumen modified with $5 \%$ EVA, plastic waste, and SBA can perform in a similar way or even demonstrate a better performance as compared to the commercial modified binder [7]. Research has shown that the rheological properties of bitumen modified with bone glue and elvaloy polymer considerably improved in terms of their susceptibility to high and low temperature conditions. However, there was no significant improvement in the viscosity of bone-glue-modified bitumen [8,9]. Another study also showed that using a mixture of (two or more) combined additives significantly improved the performance of bitumen as compared to single additive-modified bitumen [10,11].

Furthermore, moisture induces damage to the adhesion between the aggregate and bitumen, leading to the reduced strength and durability of the asphalt mixtures. In order to improve the moisture resistance in asphalt mixtures, nanomaterials (Zycosoil), lime, and SBS were used in different studies. The Zycosoil-modified bitumen was found to be very effective in making the asphalt mixture less susceptible to moisture damage. Similarly, SBS-modified bitumen with lime as a mineral filler is believed to improve the moisture resistance of the asphalt mixtures [12,13]. A study conducted by Rahman et al. (2017) [14] revealed that bitumen can be successfully replaced by $5 \%$ of cooking oil waste when the powder of CR and palm oil fuel ash (POFA) is added to achieve equal or improved stability, flow, and rutting resistance. The CR and POFA aid in controlling degradation in the cooking oil waste with the base-modified bitumen [14]. In different studies, the binder was replaced by polyethylene plastics, scrap tire rubber, coal fly ash, and straw composite fibers to improve the performance of asphalt mixtures against rutting and fatigue [15-21].

The conventional bitumen (PG 64-10), which is the only type available in the kingdom, does not meet the performance grade at high temperatures in most of the regions. Therefore, the performance grade of conventional bitumen must be improved before being used in the construction of flexible pavement. In this study, an attempt was made to use new material (date palm ash, DPA) as a bitumen modifier and to compare the results with the conventional bitumen as well as with other known additives (i.e., CR and EE-2). This study also aimed to help the environment by minimizing and recycling the CR and DPA, since the production of wastes in the KSA increases every year as a result of rapid urbanization and high population growth.

\section{Experimental Design}

\subsection{Materials}

Conventional bitumen (PG 64-10) was procured from a Riyadh refinery for the preparation of all bitumen mixes. Crumb rubber, Epolene ${ }^{\circledR}$ (EE-2), and date palm ash were used as asphalt modifiers with proportions of $4 \%, 8 \%, 12 \%$, and $16 \%$ by weight of bitumen. Crumb rubber and EE-2 were obtained from a local recycling factory in Riyadh, KSA. Meanwhile, the DPA was prepared by burning the date palms in an uncontrolled fire. Images are shown in Figure 1. Locally available limestone aggregates that meet the gradation, shown in Figure 2, were used in this study. The physical properties of bitumen and aggregates are given in Tables 1 and 2, respectively. 


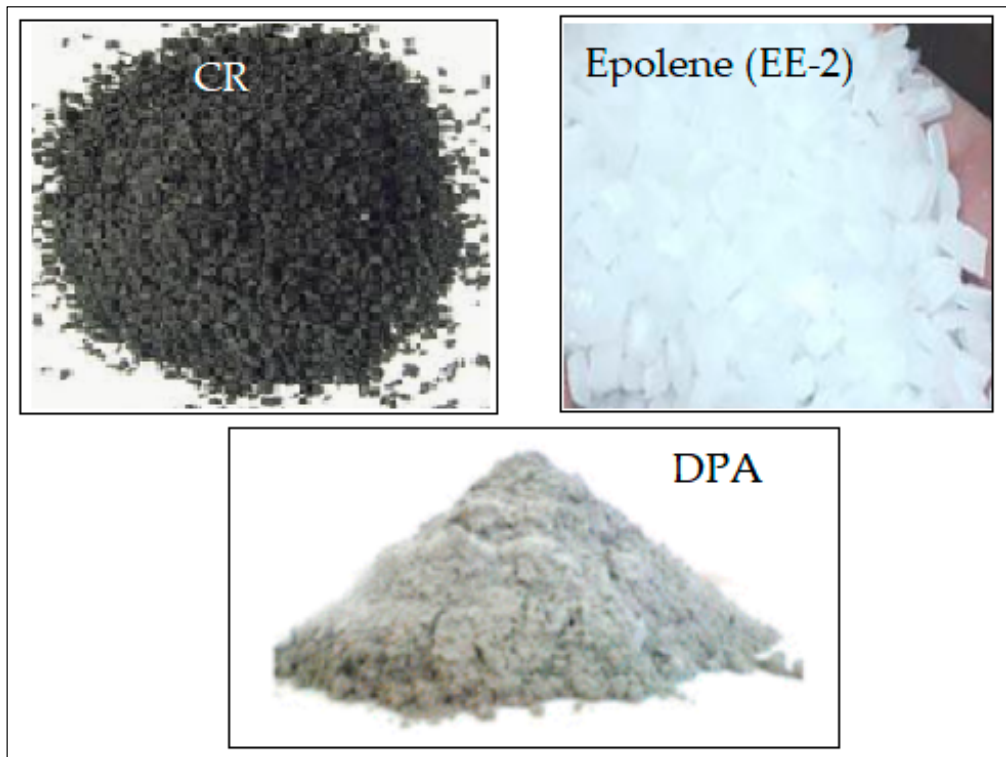

Figure 1. Images of crumb rubber (CR), Epolene ${ }^{\circledR}(\mathrm{EE}-2)$, and date palm ash (DPA).

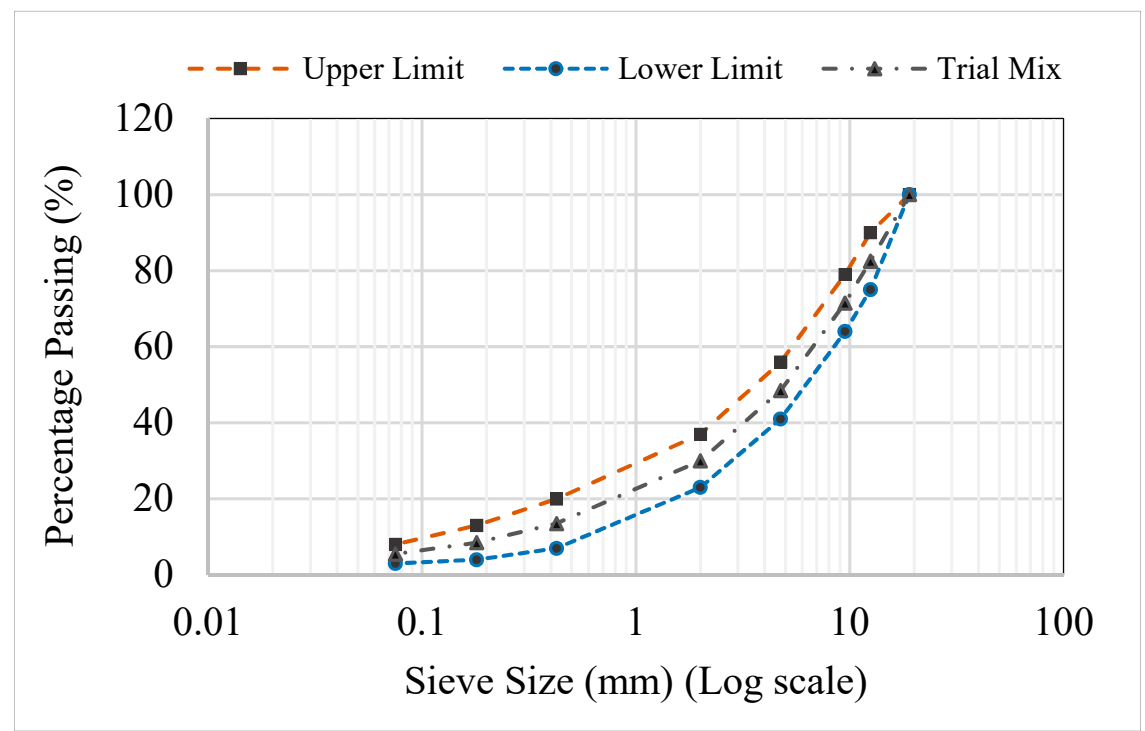

Figure 2. Aggregate gradation for the asphalt wearing course as per the Ministry of Transport (MOT)'s requirements.

Table 1. Physical properties of the aggregates.

\begin{tabular}{ccc}
\hline Physical Property/Test & Value & Standards \\
\hline Soundness Value $\left(\mathrm{Na}_{2} \mathrm{SO}_{4}\right)$ & $4.12 \%$ & $<15 \%$ \\
\hline Abrasion & $20.50 \%$ & $<40 \%$ \\
\hline $\begin{array}{c}\text { Flat and Elongated } \\
\text { Particles }\end{array}$ & $2.61 \%$ & $10 \%$ Maximum \\
\hline Sand Equivalent & $64 \%$ & $40 \%$ Minimum \\
\hline Combined Specific Gravity & 2.82 & 2.40 to 3.0 \\
\hline Water Absorption & $2.31 \%$ & $2.5 \%$ (Maximum) \\
\hline
\end{tabular}


Table 2. Physical properties of bitumen.

\begin{tabular}{ccc}
\hline Physical Property/Test & Value & Standards \\
\hline Specific Gravity & 1.021 & 1.01 to 1.06 \\
\hline Penetration @ $25^{\circ} \mathrm{C}, 0.1 \mathrm{~mm}$ & $60-70$ & Varies \\
\hline Softening point $\left({ }^{\circ} \mathrm{C}\right)$ & 48.95 & 49 to 56 \\
\hline Flash point $\left({ }^{\circ} \mathrm{C}\right)$ & 311 & 230 (Minimum) \\
\hline Ductility $(\mathrm{mm})$ & 126.4 & 100 (Minimum) \\
\hline Viscosity @ $135^{\circ} \mathrm{C}($ Pa.s) & 0.460 & 3 (Maximum) \\
\hline Super-Pave Performance Grade (PG) & $64-10$ & Depending on region \\
\hline
\end{tabular}

\subsection{Sample Preparation}

The performance grade of the base bitumen was investigated using Superpave's binder testing methods as per the ASTM standards [22-25]. Different percentages (i.e., 4\%, $8 \%, 12 \%$, and $16 \%$ ) of CR, EE-2, and DPA were blended with base bitumen for 20 minutes using high-shear laboratory mixers at a speed of $1000 \mathrm{rpm}$. The speed and time of the mixer were taken based on optimizing $\mathrm{G}^{*} / \mathrm{Sin} \delta$ (taken from our previous research) [3]. Then, a sufficient quantity of each binder was prepared and stored for further testing.

Similarly, asphalt mixtures were also prepared for the determination of the optimum bitumen content $(\mathrm{OBC})$ and for the modified mixtures. The aggregate and bitumen were heated and mixed together according to the ASTM D6926 procedure [26]. All samples were compacted with 75 blows on each face using the auto marshal compactor. Density, voids analysis, and marshal stability tests were performed to determine the optimum bitumen content [27]. All tests on the binders and mixtures were conducted in triplicate to assess their variability.

\subsection{Viscosity Test}

The viscosity of controlled and modified bitumen was determined by using a rotational viscometer (RV). Viscosity is a binder flow characteristic and it has an impact on the workability of mixing which is the ability of the asphalt binder mix to be handled and pumped at a hot mix facility. The viscosity is also used to develop a temperature viscosity chart to estimate and analyze the mixing and compaction temperature to produce and provide the best quality of mix design [28]. The viscosity of the conventional bitumen and modified bitumen was determined at a temperature of $135^{\circ} \mathrm{C}$ and a spindle speed of $20 \mathrm{rpm}$ [29]. Viscosity should not exceed 3 Pa.s because above this value more energy is consumed in mixing and compaction according to Superpave's specifications [30].

\subsection{Dynamic Shear Rheometer Tests}

Dynamic shear rheometer (DSR) tests were used to determine the visco-elastic properties of the binders, in which a thin binder sample was sandwiched between the upper and lower plates. The asphalt binders were capable of being tested at various ranges of frequency and temperature to simulate the real field conditions of pavement. The conventional as well as the modified binders were tested using a single oscillatory frequency of $1.59 \mathrm{~Hz}$ and at temperatures of 52, 58, 64, 70, 76, and $82{ }^{\circ} \mathrm{C}$. It was also used to determine the Superpave PG of the conventional and modified binders in accordance with the ASTM D6373 standards.

\subsection{Performance Tests on Marshal Samples}

The Marshall stability test was used to investigate the performance properties of the asphalt mixture specimens. The stability test was also used to determine the $\mathrm{OBC}$ in combination with specific gravity and voids analyses. Additionally, Marshall stability and Marshall flow are characteristics 
of asphalt mixtures determined from the Marshall stability apparatus. Stability is the resistance of compacted specimens against maximum vertical load, and flow is the deformation of specimens. Similarly, retained stability or aggregate adhesion with bitumen in an asphalt mix indicates the stability of a mix when exposed to water/moisture. If the materials have a high void content, the risk of stripping will be elevated which can cause the loss of aggregate-binder adhesion in the mix and disintegration of the surfacing. The Marshall samples were conditioned by keeping them in a water bath at $60{ }^{\circ} \mathrm{C}$ for $24 \mathrm{~h}$ and then tested in the Marshal stability apparatus. The retained stability was then obtained by following Equation (1):

$$
\text { Retained Stability }(\%)=100-\left(\frac{\text { Unconditioned marshall stability }(\mathrm{Kgf})}{\text { conditioned marshall stability }(\mathrm{Kgf})} \times 100\right)
$$

the recommended value of the retained stability should not be less than $75 \%$ as per the specifications of the Marshall method.

Furthermore, the Marshall-prepared samples were tested in the Marshal stability tester using an indirect tensile jig as per ASTM D6931. The height and diameter of each sample before testing were measured in accordance with ASTM D3549. The specimens were placed in a water bath for a minimum of $30 \mathrm{~min}$ at $25^{\circ} \mathrm{C}$. After conditioning, the sample was placed in between the parallel loading strips. The vertical compressive load was applied at a rate of $50 \pm 5 \mathrm{~mm} / \mathrm{min}$ and the maximum load was recorded. Equation (2) was used to estimate the indirect tensile strength value [31]:

$$
\text { ITS }=\frac{200 \times P}{\pi \times h \times D}
$$

where ITS = indirect tensile strength $\left(\mathrm{KN} / \mathrm{mm}^{2}\right) ; P=$ maximum vertical compressive load $(\mathrm{KN}) ; h=$ height of the sample $(\mathrm{mm})$, and $D=$ diameter of the sample $(\mathrm{mm})$.

\section{Results and Discussion}

The following sections describe the results obtained from various performance tests on the controlled and modified binders as well as on the asphalt mixture specimens.

\subsection{Viscosity of Binders}

Figure 3 depicts that the viscosity values of the binders, each modified with $4 \%, 8 \%, 12 \%$, and $16 \%$ of CR, EE-2, and DPA. They were all below the threshold value of the Strategic Highway Research Program (SHRP) standards, except for the 16\% CR-modified bitumen. For EE-2 and DPA, it is clear from Figure 3 that the binders with $4 \%, 8 \%$, and $12 \%$ of the additives succeeded in slightly reducing the viscosity of the control mix, providing better workability and less consumption of energy during the mixing process. On the other hand, the use of $16 \%$ EE-2 and DPA in the binders slightly increased the viscosity of the control mix compared to the original bitumen, but it was still within the limit of SHRP standards (i.e., viscosity shall be $\leq 3.0$ Pa.s). The binder replacements with DPA and EE-2 exhibited very similar viscosity behavior. However, a substantial increase in viscosity was witnessed for bitumen modified with $16 \% \mathrm{CR}$ which increased beyond the target and, hence, was not feasible for use due to the reduced workability and the need for more energy during the mixing process. 


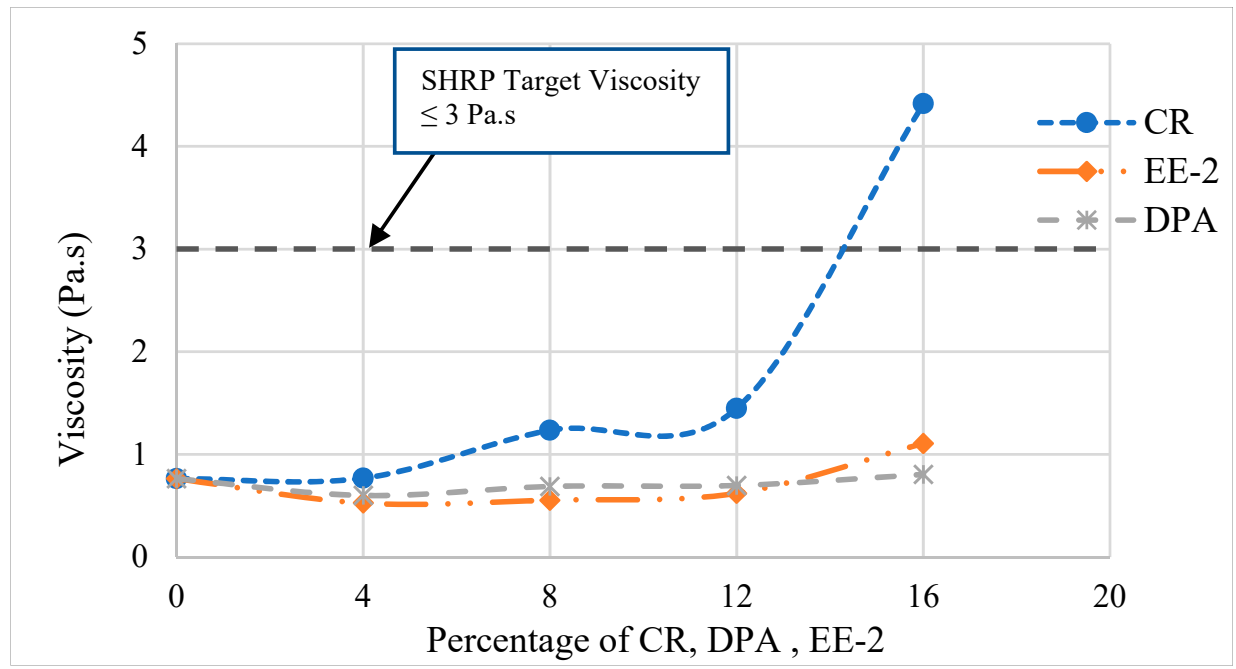

Figure 3. Viscosity of the original binder and modified binders with CR, DPA, and EE-2 with different percentages.

\subsection{Elasticity of Modified Bitumen (CR, EE-2, and DPA)}

Due to asphalt's visco-elastic nature, asphalt actions depend on the temperature rates and high loading times. The effectiveness of the temperatures and loading times were evaluated using a DSR device. Figures $4 a$, 5a and $6 a$ show the relationship between the temperature and the complex modulus which indicates the binder resistance to deformation. In Figure $6 \mathrm{a}$, the complex modulus for $4 \%$ EE-modified bitumen shows an increase and decrease at $60{ }^{\circ} \mathrm{C}$ to $66^{\circ} \mathrm{C}$, and this may be due to the development of polymer networks [32]. Figures $4 \mathrm{~b}, 5 \mathrm{~b}$ and $6 \mathrm{~b}$ show the relationship between the temperature and phase angle which indicates the binder's elasticity behavior. Figures 4-6 depict improvements in the complex modulus as well as the decrease in the phase angle with an increase in the percentage of modifier at all test temperatures $\left(46,52,58,64,70\right.$, and $\left.82^{\circ} \mathrm{C}\right)$. Hence, this improvement in the complex modulus and decrease in the phase angle gives better resistance against deformation compared to the control binder (CB). A new parameter, Glover-Rowe analysis from the frequency sweep data, can be used to predict pavement distress [33]. This parameter is more effective in predicting the low temperature and fatigue performance of the binders $[33,34]$.
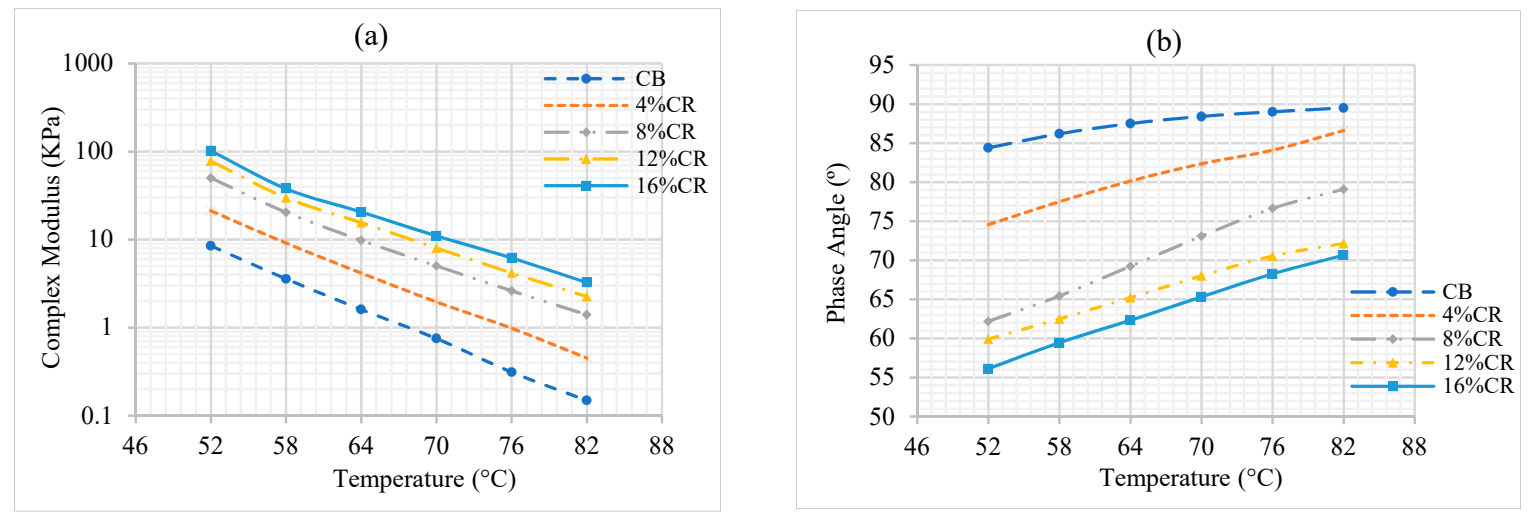

Figure 4. Effect of temperature on (a) the complex moduli and (b) the phase angles for CR. 
(a)

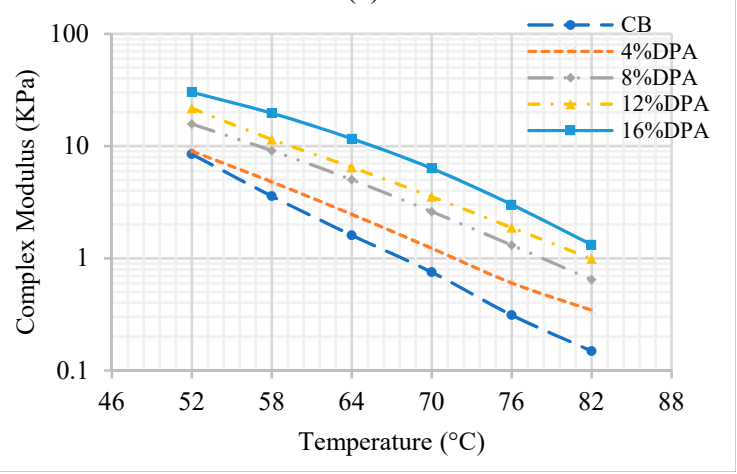

(b)

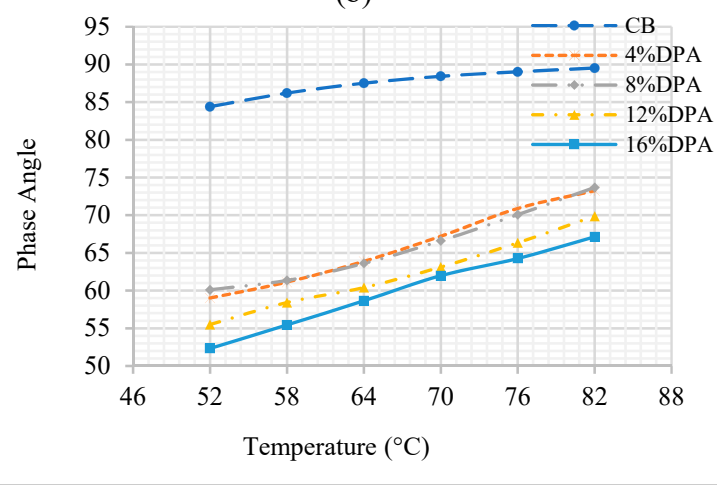

Figure 5. Effect of temperature on (a) the complex moduli and (b) the phase angles for DPA.

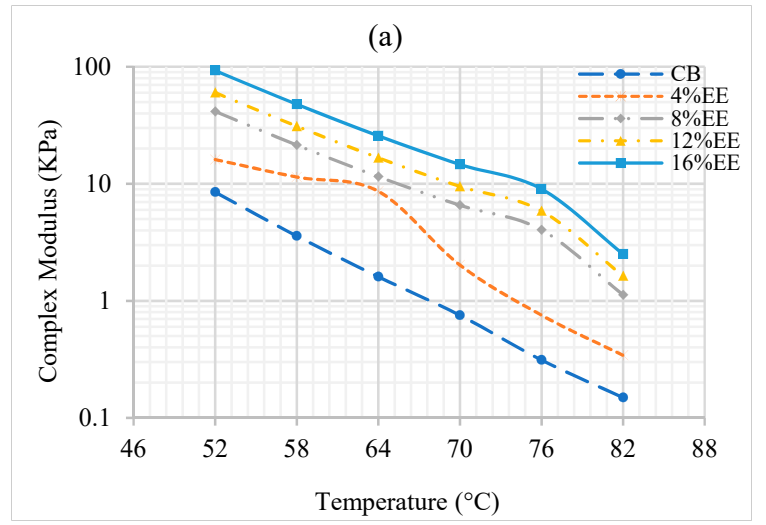

(b)

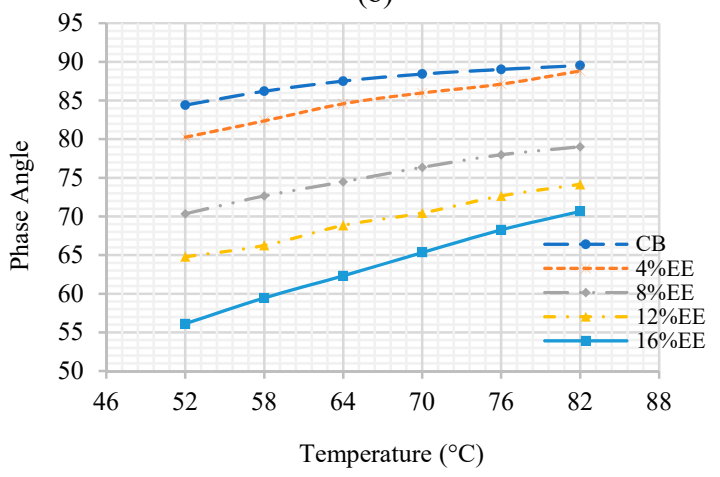

Figure 6. Effect of temperature on (a) the complex moduli and (b) the phase angles for EE-2.

\subsection{Rutting Resistance of Modified Bitumen (CR, EE-2, and DPA)}

According to Superpave's standards, asphalt fails due to the presence of rutting if the rutting parameter $\mathrm{G}^{*} / \mathrm{Sin} \delta$ drops below $1 \mathrm{KPa}$ [30]. The rutting parameter can be obtained from DSR tests $\left(G^{*} \& \delta\right)$. Hence, to improve the rutting resistance in asphalt, $G^{*} / \operatorname{Sin} \delta$ should be improved, especially in high temperature zones. Figures 6-8 show the effect of temperature on the rutting parameters of ordinary and modified binders. This predicts the performance grade for each binder where the binder fails due to the presence of rutting at temperature for which $\mathrm{G}^{*} / \mathrm{Sin} \delta$ decreases below $1 \mathrm{KPa}$.

Figures 7-9 show that the original (controlled) and modified binders met the requirements of Superpave at $\left(64{ }^{\circ} \mathrm{C}\right.$ and below). However, the controlled binder did not meet the minimum requirements of Superpave at $70{ }^{\circ} \mathrm{C}$ unlike the binder modified with CR, EE-2, and DPA which did meet the requirements of Superpave at $70{ }^{\circ} \mathrm{C}$. In fact, binders modified with $8 \%, 12 \%$, and 16 of $\mathrm{CR}$ and EE-2 met the Superpave requirements at $82{ }^{\circ} \mathrm{C}$ as well. The binders modified with $8 \%$ and $12 \%$ DPA met the Superpave requirements at $76{ }^{\circ} \mathrm{C}$, and $16 \%$ DPA reached the requirements of Superpave at $82{ }^{\circ} \mathrm{C}$. 


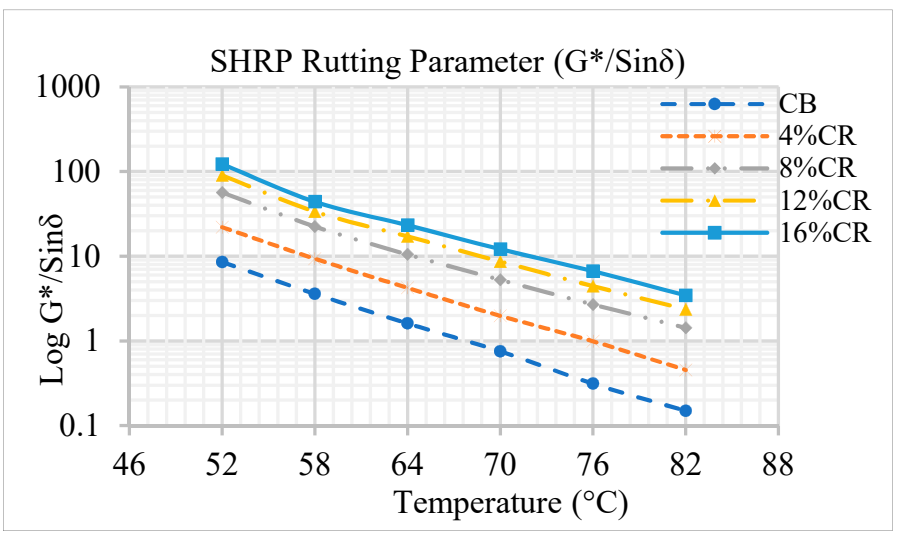

Figure 7. The temperature and modified percentage effect on the rutting parameter of CR.

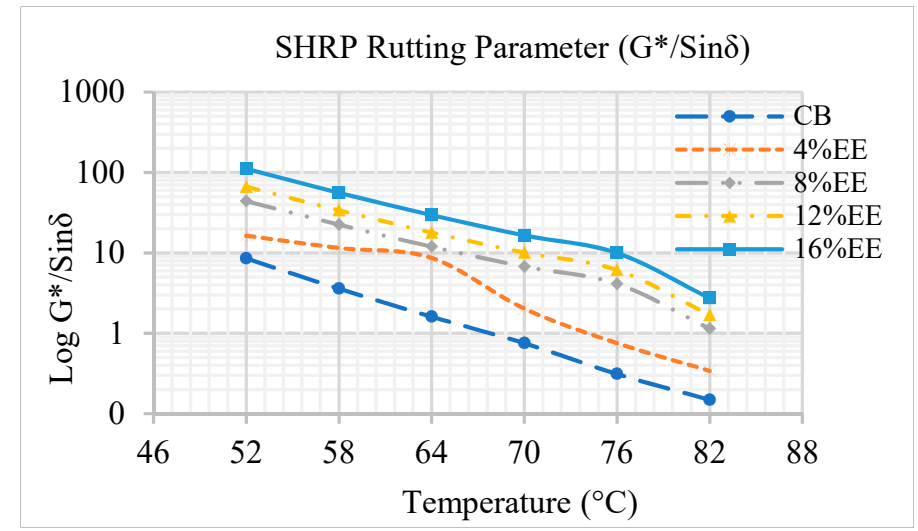

Figure 8. The temperature and modified percentage effect on the rutting parameter of EE.

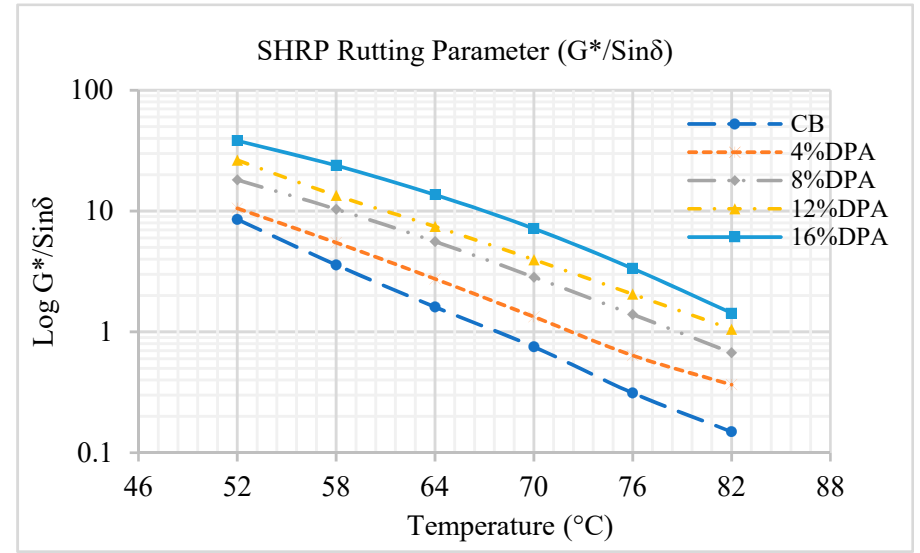

Figure 9. The temperature and modified percentage effect on the rutting parameter of DPA.

\subsection{Marshall Stability and Flow}

The test was done following ASTM D6927. Figure 10 shows and illustrates the Marshall stability and flow values that corresponded to different percentages of CR, EE-2, and DPA. It is worth mentioning that the stability of all modified mixtures was higher than the control samples. Both EE-2 and DPA showed quite similar trends in increasing the stability value to $12 \%$ and then experiencing a drop in stability at $16 \%$. However, the CR-modified samples showed a continuous increase in stability for all samples. Furthermore, 12\% DPA-modified mixtures exhibited the highest values for stability as compared to all other modifiers at the same percentage. The drop in stability beyond the $12 \%$ addition may be due to the excess amount of modifier resulting in the fact that the mix was not able to mix with the aggregate properly. Therefore, the optimum percentage of modifiers (CR, EE2, and DPA) 
was selected to be $12 \%$. Figure 10 illustrates that the Marshall flow value for CR-modified bitumen decreases with the increase in percentage of CR. In the case of EE-2-modified mixtures, the flow value showed a reduction for $8 \%$ and 12\% EE-2 and then a slight increase for 16\% EE-2. Furthermore, a different behavior was noticed in DPA-modified mixtures, and it can be seen from Figure 9 that the flow value for the DPA-modified mixtures first increased for $8 \%$, decreased for $12 \%$, and then again increased for $16 \%$.
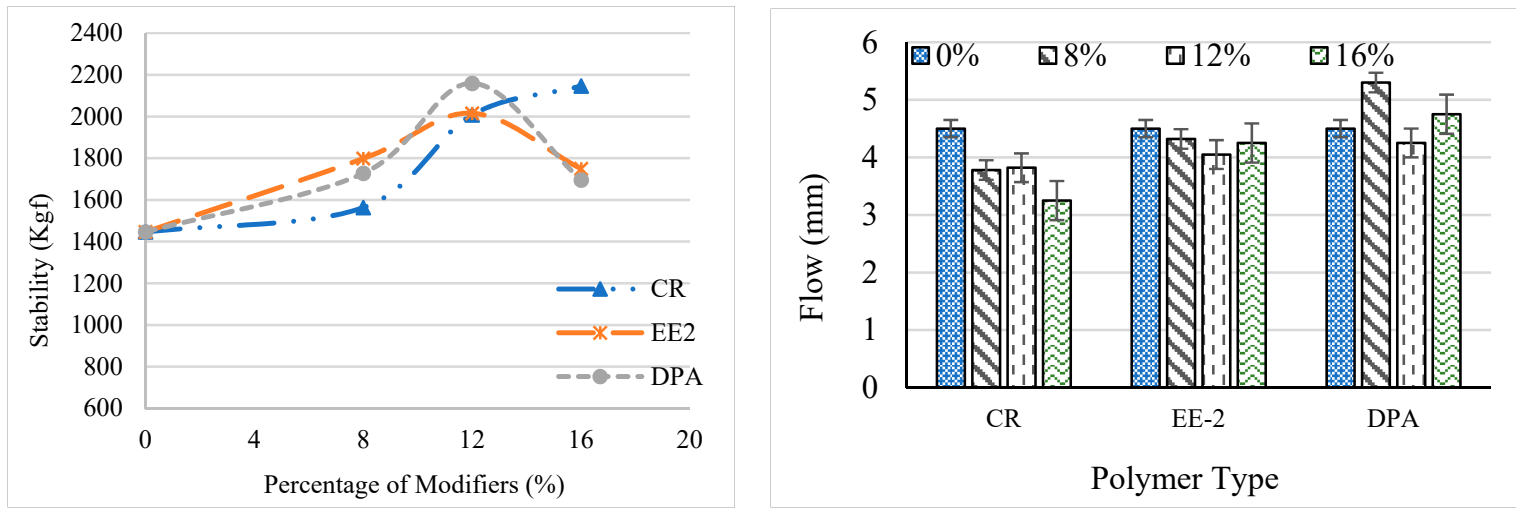

Figure 10. Marshall stability and flow of CR-, EE-2-, and DPA-modified mixtures.

\subsection{Marshall Quotient}

The Marshall quotient is the property which indicates the resistance against the deformation of an asphalt mixture, and it is calculated by dividing the Marshal stability by the flow value. A greater marshal quotient value represents its improved resistance against rutting [35,36]. From Figure 11, the highest Marshall quotient for EE2 and DPA was observed at 12\%, and CR had the highest among all the binders which was at $16 \%$. Since $16 \%$ CR does not satisfy the viscosity requirement, more energy will be required for mixing and the workability will also be affected. Therefore, it can be concluded that $12 \%$ binder replacement with CR, EE-2, and DPA can contribute to the resistance of mixtures against pavement deformation.

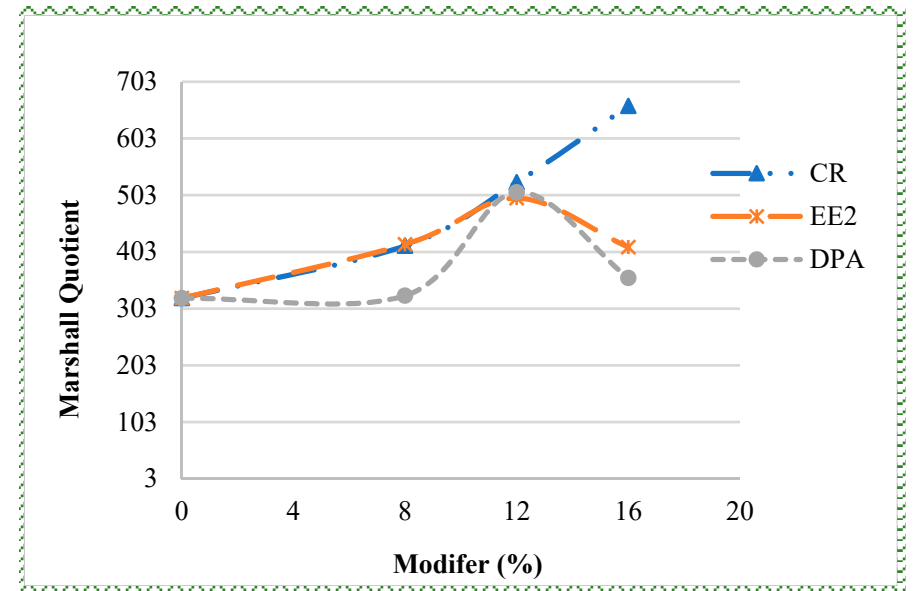

Figure 11. Marshall quotient values for different percentages of modified mixtures.

\subsection{Retained Stability}

It is clear from Figure 12 that the retained stability of all modified binders increased which indicates improvement in the binder adhesion with aggregates. Moreover, the control sample did not meet the minimum value for retained strength and, hence, stripping was likely to occur in the control samples. This is the major reason for premature failures of the surface layer due to the loss of the 
aggregate-bitumen bond following water infiltration. Furthermore, CR, EE-2, and DPA with a 12\% dosage showed the optimum retained stability.

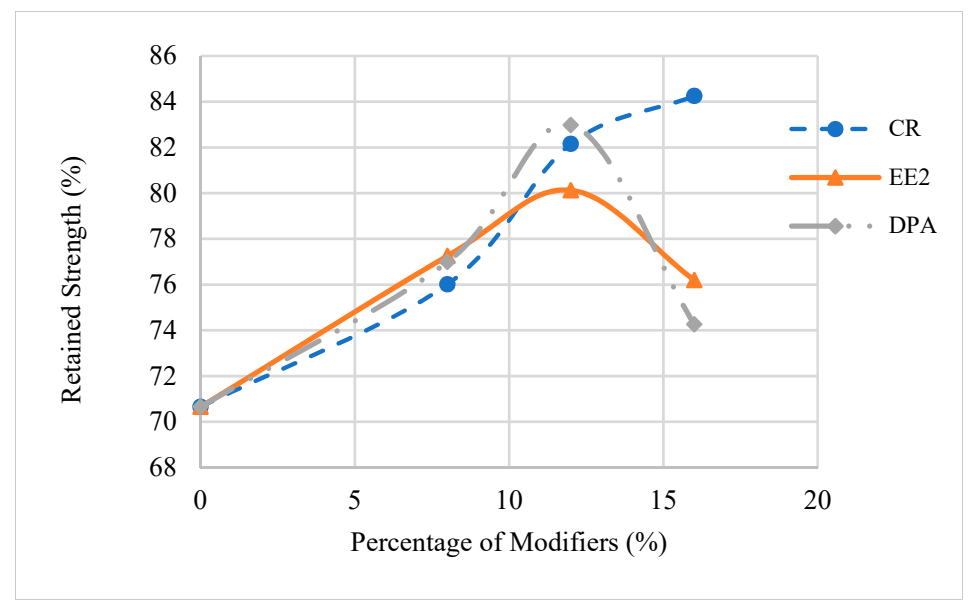

Figure 12. Retained stability for each modifier and the control sample.

\subsection{Indirect Tensile Strength of Asphalt Mixtures}

Based on the viscosity test, marshal stability, marshal quotient, and retain strength tests results, bitumen modified with $12 \%$ CR, EE-2, and DPA was considered to be the optimum dosage of the modifiers. Hence, only $12 \%$ CR, EE-2, and DPA were used to determine the indirect tensile values of the mixtures. Wen (2013) developed a new fatigue model to predict fatigue in pavement by using the fracture work density found during indirect tensile testing. It was also found that this model was effective in evaluating fatigue performance in the field; the fracture work is calculated by measuring the area under the curve of load versus displacement [37]. However, in the current study, only the maximum load was measured from IDT to evaluate the tensile strength of Marshal specimens.

It can be concluded from Figure 13, that the mixtures modified with $12 \%$ CR, EE-2, and DPA showed improved IDT strength as compared to the controlled samples. The highest tensile strength was achieved using a 12\% CR-modified mixture, whereas 12\% EE-2 and 12\% DPA exhibited similar results to each other as confirmed below by the statistical analysis.

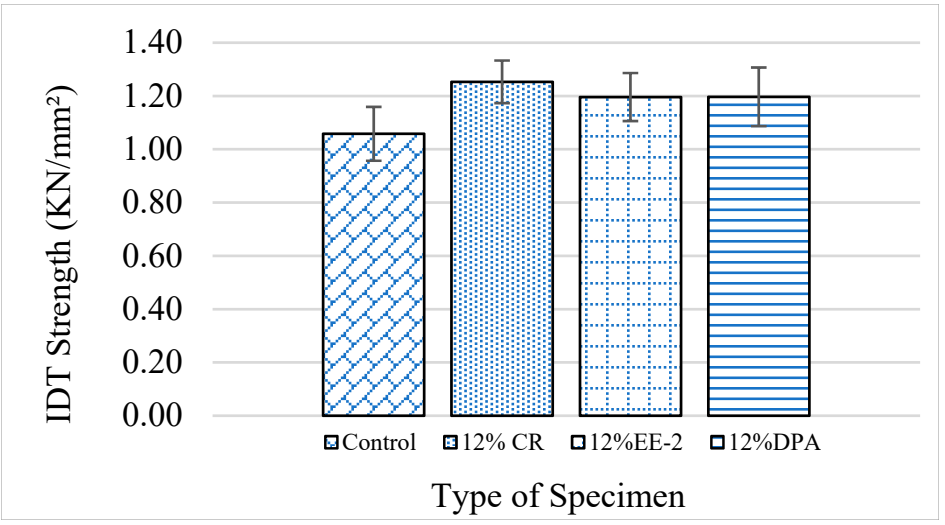

Figure 13. Indirect tensile tests for each modifier at $12 \%$ replacement by weight of bitumen.

Statistical analysis using a significance level of $0.05(\alpha=0.05)$ was conducted to come to a conclusion regarding the $12 \%$ EE- 2 and $12 \%$ DPA results. A $t$-test was conducted using triplicate results from the EE-2 and DPA mixtures as shown in Table 3. 
Table 3. Statistical analysis of the results for verification of similarity.

\begin{tabular}{ccc}
\hline & Variable 1 (12\% EE-2) & Variable 2 (12\% DPA) \\
\hline Mean & 1.195966667 & 1.1968 \\
Variance & 0.600969703 & 0.60046707 \\
$t$-Stat & -1.386750491 & \\
$p$-Value, $(\mathrm{T} \leq \mathrm{t})$ one-tail & 0.149929979 & \\
$t$-Value, critical one-tail & 2.91998558 & \\
$p$-Value, $(\mathrm{T} \leq \mathrm{t})$ two-tail & 0.299859958 & \\
$t$-Value, critical two-tail & 4.30265273 & \\
\hline
\end{tabular}

It can be seen from the analysis that the $p$-values (both one tail and two tail) were greater than $\alpha$. This indicates that there was weak evidence against the null hypothesis and, hence, the results for $12 \%$ EE-2 and $12 \%$ DPA were similar to each other.

\section{Conclusions}

Based on the above stated results and discussion, the following conclusions were derived:

1. There was a slight reduction in the viscosity of the binder modified with $4 \%, 8 \%$, and $12 \%$ EE-2 and DPA as compared to the base bitumen. This will result in better workability and lower energy consumption during the mixing process. Meanwhile, CR-modified bitumen results in an increase in the viscosity of the binder. However, the viscosity of binder modified with $4 \%, 8 \%$, and $12 \%$ $\mathrm{CR}$ was still below the Superpave specifications (viscosity $\leq 3$ Pa.s) and can be used as bitumen replacement up to $12 \%$ by weight of bitumen.

2. The visco-elastic behavior of binder was significantly affected by the increase in the temperature and percentage of CR, EE-2, and DPA as a bitumen replacement. The modified binders showed improved elasticity, as compared to the base bitumen, due to the increase in complex modulus $\left(G^{*}\right)$ and the reduction in the phase angle values. Similarly, the increase in temperature caused a decline in the complex modulus because of the viscous behavior of bitumen.

3. Binders modified with CR, EE-2, and DPA had significantly improved SHRP rutting parameters $\left(\mathrm{G}^{*} / \mathrm{Sin} \delta\right)$ at high temperature. At a temperature of $70{ }^{\circ} \mathrm{C}$, all modified binders met the minimum requirement for rutting resistance. However, $4 \%$ EE-2 and $4 \%$ DPA did not meet the minimum requirement at $76{ }^{\circ} \mathrm{C}$. Furthermore, the high-temperature performance grade of base binder (PG64-10) improved to PG76 for 8\%-16\% CR, EE-2, and DPA.

4. The binder modified with CR ( $8 \%-12 \%)$, EE-2 (8\%-12\%), and DPA (12\%-16\%) also met the minimum SHRP rutting criteria $\left(\mathrm{G}^{*} / \operatorname{Sin} \delta \geq 1 \mathrm{kPa}\right)$ at the highest temperature $\left(82{ }^{\circ} \mathrm{C}\right)$. Therefore, these modified binders can be used in flexible pavement construction in the hottest KSA regions.

5. The Marshall stability and Marshall quotient values showed improvement for mixtures modified with CR, EE-2, and DPA up to $12 \%$ and then a drastic reduction in the Marshal stability and Quotient values, except for CR. Hence, the mixtures modified with $12 \%$ CR, EE-2, and DPA showed maximum stability and Marshall quotient values and, hence, improved resistance against deformation. Despite having the highest Marshall stability and marshal quotient values, $16 \%$ CR was not feasible due the fact of its high viscosity values.

6. The retained stability of mixtures modified with CR, EE-2, and DPA showed significant improvement as compared to the non-modified mixtures; this indicates that these mixtures were less susceptible to moisture and, hence, there was strong adhesion (bond) between the aggregate and modified binders.

7. Similarly, the indirect tensile strength for the mixtures modified with $12 \% \mathrm{CR}$, EE-2, and DPA showed very similar behavior but a slight improvement as compared to the controlled mixed specimens. 
Author Contributions: M.I.K. designed the research and performed the experiments; M.I.K., M.H.S. and S.R. analyzed the experimental results; M.I.K. M.H.S., S.S., S.R. and N.I.M.Y. wrote the paper.

Funding: The authors would like to thank King Faisal University, KSA, for the financial support through the "Deanship of Scientific Research" at King Faisal University (KFU) (Project \#160172). The authors are also thankful to Universiti Teknologi Petronas (UTP), Malaysia and Universitas Muhammadiyah Surakarta, Indonesia for their financial support as well.

Conflicts of Interest: The authors declare no conflict of interest.

\section{References}

1. Wahhab, H.I.A.-A.; Asi, I.M.; Al-Dubabe, I.A.; Ali, M.F. Development of performance-based bitumen specifications for the Gulf countries. Constr. Build. Mater. 1997, 11, 15-22. [CrossRef]

2. Zhu, J.; Birgisson, B.; Kringos, N. Polymer modification of bitumen: Advances and challenges. Eur. Polym. J. 2014, 54, 18-38. [CrossRef]

3. Amin, M.; Khan, M.; Saleem, M. Performance evaluation of asphalt modified with municipal wastes for sustainable pavement construction. Sustainability 2016, 8, 949. [CrossRef]

4. Khan, I.M.; Kabir, S.; Alhussain, M.A.; Almansoor, F.F. Asphalt design using recycled plastic and crumb-rubber waste for sustainable pavement construction. Procedia Eng. 2016, 145, 1557-1564. [CrossRef]

5. Yousefi, A.A. Polyethylene dispersions in bitumen: The effects of the polymer structural parameters. J. Appl. Polym. Sci. 2003, 90, 3183-3190. [CrossRef]

6. Hınıslığlu, S.; Ağar, E. Use of waste high density polyethylene as bitumen modifier in asphalt concrete mix. Mater. Lett. 2004, 58, 267-271. [CrossRef]

7. Othman, A.M. Effect of low-density polyethylene on fracture toughness of asphalt concrete mixtures. J. Mater. Civ. Eng. 2010, 22, 1019-1024. [CrossRef]

8. Costa, L.M.; Silva, H.; Oliveira, J.R.; Fernandes, S.R. Incorporation of waste plastic in asphalt binders to improve their performance in the pavement. Int. J. Pavement Res. Technol. 2013, 6, 457-464.

9. Rizvi, H.R.; Khattak, M.J.; Gallo, A.A. Rheological and mechanistic characteristics of Bone Glue modified asphalt binders. Constr. Build. Mater. 2015, 88, 64-73. [CrossRef]

10. Hafeez, I.; Hussain, J.; Riaz, K.; Khitab, A.; Hussain, S.; Zaidi, B.; Farooqi, U.; Hayat, A.; Ahmed, I.; Asif, A. Influence of Time and Temperature on Asphalt Binders Rheological Properties. Life Sci. J. 2013, 10, 894-898.

11. Kök, B.V.; Yılmaz, M.; Akpolat, M. Evaluation of the conventional and rheological properties of SBS+ Sasobit modified binder. Constr. Build. Mater. 2014, 63, 174-179. [CrossRef]

12. Nejad, F.M.; Azarhoosh, A.; Hamedi, G.H.; Azarhoosh, M. Influence of using nonmaterial to reduce the moisture susceptibility of hot mix asphalt. Constr. Build. Mater. 2012, 31, 384-388. [CrossRef]

13. Kok, B.V.; Yilmaz, M. The effects of using lime and styrene-butadiene-styrene on moisture sensitivity resistance of hot mix asphalt. Constr. Build. Mater. 2009, 23, 1999-2006. [CrossRef]

14. Rahman, M.T.; Hainin, M.R.; Bakar, W.A.W.A. Use of waste cooking oil, tire rubber powder and palm oil fuel ash in partial replacement of bitumen. Constr. Build. Mater. 2017, 150, 95-104. [CrossRef]

15. Hasan, M.R.M.; Colbert, B.; You, Z.; Jamshidi, A.; Heiden, P.A.; Hamzah, M.O. A simple treatment of electronic-waste plastics to produce asphalt binder additives with improved properties. Constr. Build. Mater. 2016, 110, 79-88. [CrossRef]

16. Ge, D.; Yan, K.; You, Z.; Xu, H. Modification mechanism of asphalt binder with waste tire rubber and recycled polyethylene. Constr. Build. Mater. 2016, 126, 66-76. [CrossRef]

17. Fang, C.; Zhang, M.; Yu, R.; Liu, X. Effect of preparation temperature on the aging properties of waste polyethylene modified asphalt. J. Mater. Sci. Technol. 2015, 31, 320-324. [CrossRef]

18. Yu, R.; Fang, C.; Liu, P.; Liu, X.; Li, Y. Storage stability and rheological properties of asphalt modified with waste packaging polyethylene and organic montmorillonite. Appl. Clay Sci. 2015, 104, 1-7. [CrossRef]

19. Wu, X.; Wang, S.; Dong, R. Lightly pyrolyzed tire rubber used as potential asphalt alternative. Constr. Build. Mater. 2016, 112, 623-628. [CrossRef]

20. Bautista, E.G.; Flickinger, J.; Saha, R.; Flores-Vivian, I.; Faheem, A.F.; Sobolev, K. Effect of coal combustion products on high temperature performance of asphalt mastics. Constr. Build. Mater. 2015, 94, 572-578. [CrossRef] 
21. Xue, Q.; Liu, L.; Chen, Y.-J. Study on the action effect of pavement straw composite fiber material in asphalt mixture. Constr. Build. Mater. 2013, 43, 293-299.

22. ASTM D7175-08. Standard Test Method for Determining the Rheological Properties of Asphalt Binder Using a Dynamic Shear Rheometer; ASTM International: West Conshohocken, PA, USA, 2008.

23. ASTM-D2872-04. Standard Test Method for Effect of Heat and Air on a Moving Film of Asphalt (Rolling Thin-Film Oven Test); ASTM International: West Conshohocken, PA, USA, 2012.

24. ASTM-D6521-08. Standard Practice for Accelerated Aging of Asphalt Binder Using a Pressurized Aging Vessel (PAV); ASTM International: West Conshohocken, PA, USA, 2013.

25. ASTM-D6648-08. Standard Test Method for Determining the Flexural Creep Stiffness of Asphalt Binder Using the Bending Beam Rheometer (BBR); ASTM International: West Conshohocken, PA, USA, 2001.

26. ASTM-D6926-16. Standard Practice for Preparation of Asphalt Mixture Specimens Using Marshall Apparatus; ASTM International: West Conshohocken, PA, USA, 2016.

27. ASTM-D6927-15. Standard Test Method for Marshall Stability and Flow of Asphalt Mixtures; ASTM International: West Conshohocken, PA, USA, 2015.

28. Cardone, F.; Ferrotti, G.; Frigio, F.; Canestrari, F. Influence of polymer modification on asphalt binder dynamic and steady flow viscosities. Constr. Build. Mater. 2014, 71, 435-443. [CrossRef]

29. ASTM-D4402-15. Standard Test Method for Viscosity Determination of Asphalt at Elevated Temperatures Using a Rotational Viscometer; ASTM International: West Conshohocken, PA, USA, 2015.

30. Asphalt-Institute. Superpave: Performance Graded Asphalt Binder Specification and Testing; Asphalt Institute: Park Drive Lexington, KY, USA, 2000.

31. ASTM-D6931. Standard Test Method for Indirect Tensile (IDT) Strength of Bituminous Mixtures; ASTM International: West Conshohocken, PA, USA, 2007.

32. Abdelaziz, M.; Mohamed Rehan, K. Rheological evaluation of bituminous binder modified with waste plastic material. In Proceedings of the 5th International Symposium on Hydrocarbons \& Chemistry (ISHC5), Sidi Fredj, Algiers, 23-25 May 2010.

33. Mensching, D.J.; Jacques, C.D.; Daniel, J.S. Applying the glover-rowe parameter to evaluate low-temperature performance of hot mix asphalt LTPP sections. J. Mater. Civ. Eng. 2016, 28, 04016096. [CrossRef]

34. Rowe, G.; King, G.; Anderson, M. The influence of binder rheology on the cracking of asphalt mixes in airport and highway projects. J. Test. Eval. 2014, 42, 1063-1072. [CrossRef]

35. Ameri, M.; Behnood, A. Laboratory studies to investigate the properties of CIR mixes containing steel slag as a substitute for virgin aggregates. Constr. Build. Mater. 2012, 26, 475-480. [CrossRef]

36. Taherkhani, H.; Arshadi, M.R. Investigating the mechanical properties of asphalt concrete containing waste polyethylene terephthalate. Road Mater. Pavement Des. 2019, 20, 381-398. [CrossRef]

37. Wen, H. Use of fracture work density obtained from indirect tensile testing for the mix design and development of a fatigue model. Int. J. Pavement Eng. 2013, 14, 561-568. [CrossRef] 